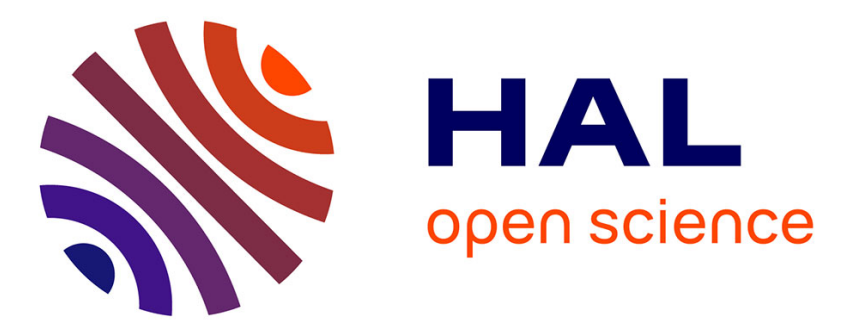

\title{
An ionic liquid-based extraction system using diglycolamide functionalized macrocyclic platforms for the extraction and recovery of lanthanides
}

\author{
M. Wehbie, Guilhem Arrachart, L. Ghannam, I. Karame, S Pellet-Rostaing
}

\section{- To cite this version:}

M. Wehbie, Guilhem Arrachart, L. Ghannam, I. Karame, S Pellet-Rostaing. An ionic liquid-based extraction system using diglycolamide functionalized macrocyclic platforms for the extraction and recovery of lanthanides. Dalton Transactions, 2017, 46 (47), pp.16505-16515. 10.1039/c7dt02797d . hal-02062517

\section{HAL Id: hal-02062517 \\ https://hal.science/hal-02062517}

Submitted on 26 Oct 2021

HAL is a multi-disciplinary open access archive for the deposit and dissemination of scientific research documents, whether they are published or not. The documents may come from teaching and research institutions in France or abroad, or from public or private research centers.
L'archive ouverte pluridisciplinaire HAL, est destinée au dépôt et à la diffusion de documents scientifiques de niveau recherche, publiés ou non, émanant des établissements d'enseignement et de recherche français ou étrangers, des laboratoires publics ou privés. 


\title{
An ionic liquid-based extraction system using diglycolamide functionalized macrocyclic platforms for the extraction and recovery of lanthanides
}

\author{
M. Wehbie, ${ }^{a, b}$ G. Arrachart, ${ }^{* a}$ L. Ghannam, ${ }^{b}$ I. Karaméb and S. Pellet-Rostaing *a \\ aICSM, CEA, CNRS, Univ. Montpellier, ENSCM, Bagnols-sur-Cèze, France. \\ bLCOM, Department of Chemistry, Lebanese University, Faculty of Sciences I, Hadath, Lebanon \\ *Corresponding author. E-mail: guilhem.arrachart@cea.fr , stephane.pellet-rostaing@cea.fr
}

Solvent extraction of lanthanides $\operatorname{Ln}(\mathrm{III})$ (La, Eu and $\mathrm{Yb}$ ) with resorcin[4]arene cavitand-triazole-DODGA (CR4-TZ-DODGA) and tbutylcalix[4]arene-triazole-DODGA (C4-TZ-DODGA) has been studied in a room temperature ionic liquid (RTIL), N-octyl-Nethylpiperidiniumbis(trifluoromethylsulfonyl)imide ([EOPip]NTf2). The two macrocyclic platforms were functionalized with four diglycolamide (DGA) moietiesthanks to a click reaction and fully characterized by NMR and MS analysis. The effects of acidity as well as the concentration of the ligands were investigated on the extraction and separation properties. The parameters of the extraction processes were determined by the slope method and thermodynamic studies. For both ligands, the extraction efficiency changes along the lanthanoid series with selectivity toward $\mathrm{Yb}$ (III) in regard to $\mathrm{La}(\mathrm{III})$ and $\mathrm{Eu}(\mathrm{III})$. The selective extraction and recovery of lanthanides from a simulated leaching solution of a $\mathrm{Nd} / \mathrm{Fe} / \mathrm{B} / \mathrm{Dy}$ magnet has also been investigated.

\section{Introduction}

Rare earth elements (REEs) including lanthanides (Ln) play an essential role in our everyday life; these highly technical elements are widely used in different domains such as high technology (cell phones, LCD panels, disk drives, etc.), renewable energy (wind turbines), rechargeable batteries, etc. The forecast for their average annual demand is an increase by more than $8 \%$ every year by $2020 .{ }^{1}$ In terms of supply of REEs, China produces roughly $80 \%$ of the world's supply of REEs. In contrast to the increasing REE demand, the supply of such materials is currently experiencing a shortage, and they are considered as critical for the western nations (EU and US). ${ }^{2}$ Alternatives that can be used to reduce the stress on the rare earth supply can be opening of new REE deposits or efforts to recycle these elements particularly from end-of life products such as the Waste of Electrical and Electronic Equipment's (WEEE). ${ }^{3}$

Whatever the resources, mines, secondary resources or WEEEs, these elements can be extracted by hydrometallurgy involving their dissolution and recovery. Despite its efficiency to separate and purify REEs, this method has some drawbacks due to the use of classical diluents which could be toxic, flammable and then responsible for the emission of VOCs in the atmosphere.

Ionic liquids (ILS) exhibit several properties that make them attractive for the replacement of common organic diluents; these properties are a wide liquid range, good thermal stability, the ability to solubilize a wide range of solutes, a very low vapour pressure, and nonflammability. ${ }^{4-6}$ In most of the examples described in the literature, ${ }^{7,8}$ when passing from atraditional organic solvent to an ionic liquid, a remarkable extraction efficiency is obtained. Usually, it appears also that the extraction mechanism is very different. ${ }^{9}$ Depending on the nature of the ligand, the IL and the aqueous phase, mechanisms such as ion-exchange, neutral coextraction or neutral solvation can be encountered. ${ }^{10}$

Since the first extraction using crown ethers in ILs introduced by Dai et al., ${ }^{11}$ numerous studies concerning the extraction of lanthanides and actinides by using well-known extractants dissolved in ILs such as CMPO, ${ }^{12,13}$ DGA, ${ }^{14}$ malonamides, ${ }^{15,16}$ Cyanex925, ${ }^{17}$ phosphine oxide, ${ }^{18}$ trialkyl amine, ${ }^{19}$ and even synergistic systems such as HDEHP/TOPO have been published. ${ }^{20}$

Among all extractants, diglycolamides (DGA) have gained specific importance since first reported by Stephan and coworkers in 1991.21,22 Diglycolamides have special characteristics because they are tridentate ligands containing three oxygen atoms, which can allow them to form stable complexes with lanthanides and actinides. ${ }^{23-25}$ Verboom et al. showed that the organization of DGA sites on pre-organized macrocyclic platforms can have superior efficiency even at 100 times lower concentration than N,N,N,N-tetra(n-octyl)diglycolamide (TODGA) itself. $26-28$

Unlike the extraction in classical solvents, the extraction using neutral extractants such as DGA ligands in ILs can proceed through a cationic, an anionic or a solvation mechanism as a function of the IL involved. ${ }^{14,26,29}$ The ion-exchange mechanism is often presented as a major drawback for the potential applications of ILs in liquid-liquid extraction due to the loss of IL cations/anions into the aqueous phase. Ideally, the ion-exchange has to be minimized or suppressed without losing its positive effects on the performance of ILs.

In the present work, two macrocyclic ligands, based on the resorcinarene cavitand and calixarene platform, with DGA moieties have been synthesized using a click reaction (Fig. 1). The success of the cycloaddition reactions of the DGA moieties on the platforms has been monitored by FT-IR, NMR and MS analysis. In order to minimize a partitioning mechanism in which the metal ion transfer is accompanied by a loss of the IL cation to the aqueous phase, a hydrophobic room temperature ionic liquid (RTIL), N-octyl-N-ethylpiperidinium bis(trifluoromethylsulfonyl)imide ([EOPip]NTf2), has been used as the diluent for the extraction experiments. 1-Octanol (10\% v) was added to the IL phase in order to avoid the formation of a third phase or precipitate, this also helps to decrease the viscosity of the IL phase. 

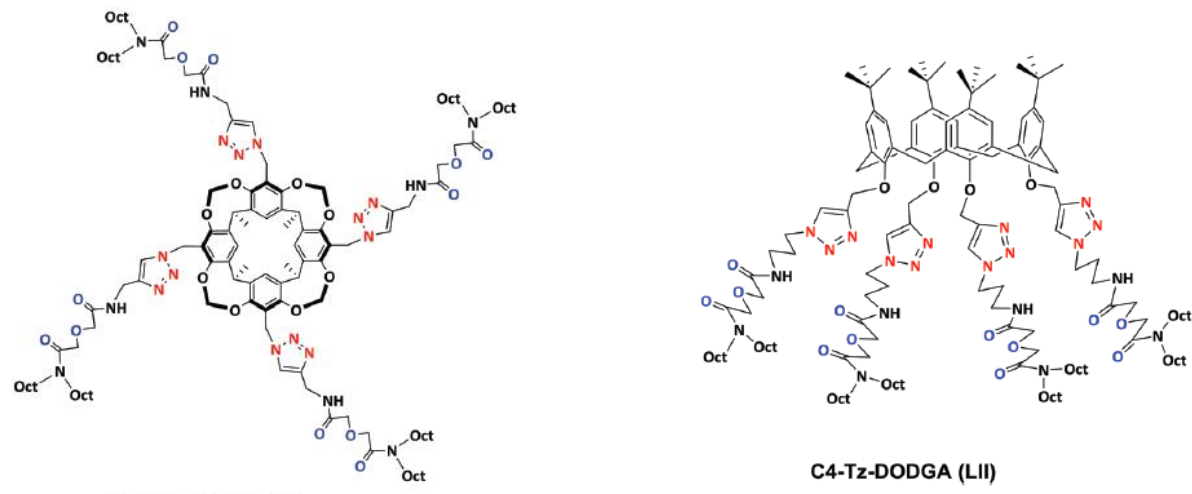

C4-Tz-DODGA (LII)

CR4-Tz-DODGA (LI)

Fig. 1 Structural formulas of CR4-TZ-DODGA (LI) and C4-TZ-DODGA (LII) (for clarity the bond angles do not represent the actual angles of the ligands).

The performance of both chelating macrocycles in the IL phase has been evaluated toward the extraction of three lanthanides Ln(III) (La, $\mathrm{Eu}$ and $\mathrm{Yb}$ ) under nitric acidic feed conditions. The stoichiometries of the complexes and the thermodynamic parameters during the extraction of the complexes were estimated for both ligands at a low nitric acid concentration $\left(0.01 \mathrm{M} \mathrm{HNO}_{3}\right)$.

In the case of the resorcin[4]arene cavitand platform (CR4-TZ-DODGA), the results obtained in the IL phase (the present work) were compared with previous experiments performed in toluene/iso-octanol as the diluent system. ${ }^{30}$ Extraction and stripping of a simulated solution of permanent magnets containing Fe-B-Nd-Dy have been performed and both ligands showed high selectivity toward lanthanides in regard to other elements.

\section{Results and discussion}

\section{Synthesis}

CR4-TZ-DODGA was synthesized as described in our previous work. ${ }^{30}$ C4-TZ-DODGA was obtained via a different way based on a general synthetic route in four steps according to Fig. 2. The azido propylamine 1 was obtained by treating bromopropylamine hydrobromide with sodium azide. Then the "azide-DGA" 3 was obtained by amide coupling of azido ethylamine with DODGA 2 using DCC as a coupling agent in the presence of $\mathrm{HOBt} .{ }^{30,31}$

The introduction of clickable alkyne functions on the calix[4]arene platform was performed by the reaction of propargylbromide and tertbutylcalix[4]arene as described in the literature ${ }^{32}$ (Fig. 2). ${ }^{1} \mathrm{H}-\mathrm{NMR}$ spectra of compounds 3 and 4 are in accordance with the expected structures (see the experimental part).

The success of the functionalization of the calix[4]arene platform 4 by DGA units using a click reaction has been monitored by $\mathrm{FT}-\mathrm{IR}$, ${ }^{1 \mathrm{H}} \mathrm{H}$ NMR, ${ }^{13}$ C-NMR, DEPT135, COSY, and HSQC in addition to ESI-MS (see Fig. S-1-S-4 in the ESI).
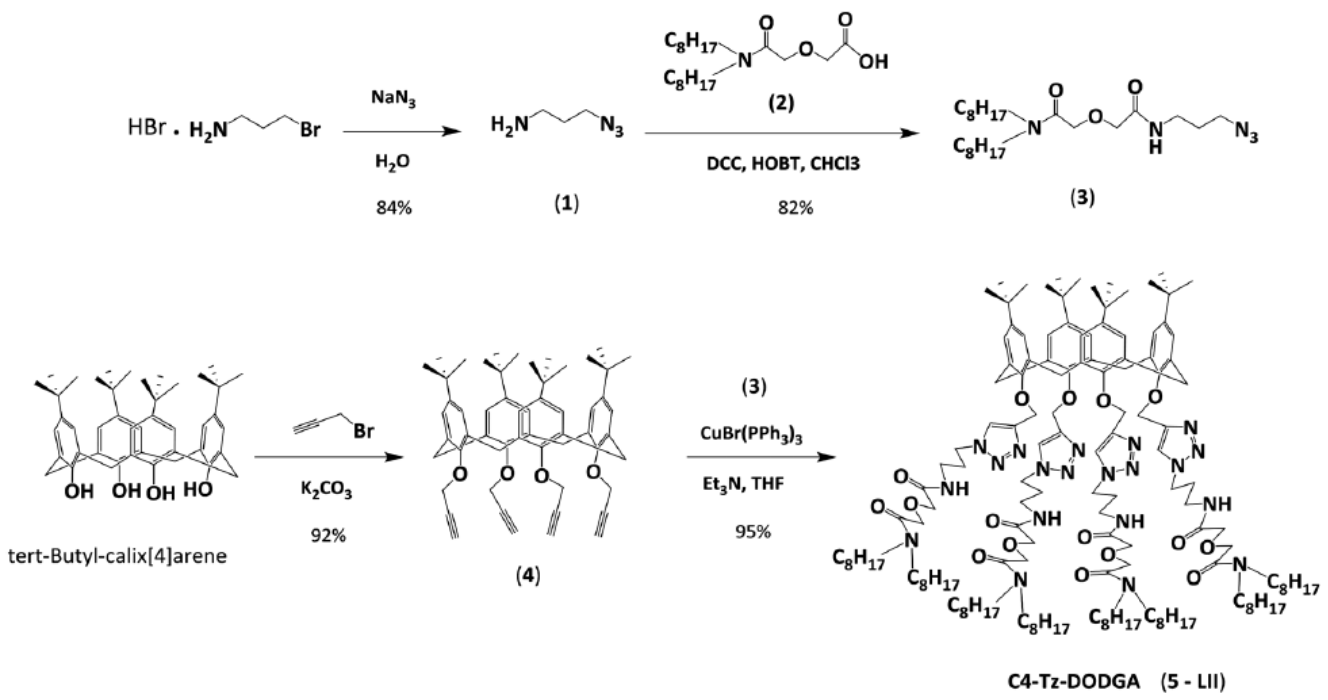

Fig. 2 Synthesis scheme for C4-TZ-DODGA (LII). 
The complete disappearance of the azide stretching vibration at $2090 \mathrm{~cm}^{-1}$ in the IR spectra, the alkyl-H resonance signal at $2.5 \mathrm{ppm}$ in the ${ }^{1} \mathrm{H}-\mathrm{NMR}$ spectra, and the appearance of the triazole-H at $7.92 \mathrm{ppm}$ confirm the complete conversion of the N3 groups of the azide-DGA (3) and the alkyne group of the calix[4]arene platform 4 into triazole functionalities.

The success of the cycloaddition reaction was also confirmed by two resonance signals at 124.64 and 144.23 ppm in ${ }^{13} \mathrm{C}$-NMR spectra, characteristic of 1,4-disubstituted 1,2,3-tri-azoles. In addition, the DGA side arms are identified by two resonance signals of the $\mathrm{CH}_{2}$ methylene groups at 69.62 and 71.76 ppm and two other signals at 169.99 and $168.2 \mathrm{ppm}$ in the ${ }^{13} \mathrm{C}-\mathrm{NMR}$ spectra, corresponding to the amide carbonyl groups.

\section{Liquid-liquid extraction}

To evaluate the extraction performance of the ligands, $\mathrm{La}(\mathrm{III})$, $\mathrm{Eu}(\mathrm{III})$ and $\mathrm{Yb}(\mathrm{III})$ were used as representative light, middle, and heavy lanthanides, respectively. In the present study, N-octyl-Nethylpiperidiniumbis(trifluoromethylsulfonyl)imide ([EOPip]NTf2) with 1-octanol $(10 \% \mathrm{v})$ was chosen as a lipophilic diluent and modifier. This choice was driven by the fact that the cation-exchange mechanism which proceeds through a loss of the IL cation into the aqueous phase can be avoided by increasing the hydrophobicity of the IL by using cations with fatty alkyl chains. ${ }^{33,34}$ The addition of 1-octanol enhances the solubilisation of the ligands, prevents the formation of the third phase during the extraction, and helps to reduce the viscosity of the IL phase.

The partitioning of lanthanides into the IL phase without ligands was found to be negligible as already observed in the literature. ${ }^{18}$ No extraction of Ln by the [EOPip]NTf2 was observed whatever the nitric acid concentration of the aqueous phase. A recent study on the triazole diglycolamide cavitand showed that the triazole rings are not involved in the Ln extraction and the latter took place only due to the preorganization of the diglycolamide on the cavitand. ${ }^{35}$

The extraction behaviour of lanthanides with CR4-TZ-DODGA (LI) and C4-TZ-DODGA (LII) in the IL phase as a function of the concentration of ligands and $\mathrm{HNO}_{3}$ concentration in the aqueous phase has been studied.

\section{Effect of nitric acid concentration}

The distribution and selectivity values for the extraction of $\mathrm{La}^{3+}$, $\mathrm{Eu}^{3+}$, and $\mathrm{Yb}^{3+}$ with $\mathrm{LI}$ and $\mathrm{LII}$ at different feed acidities from 0.001 to $3 \mathrm{M}$ nitric acid are illustrated in Fig. 3.

The presented data for the extraction of Ln(III) with LI and LII show that the extraction efficiency of lanthanides was slightly reduced with increasing $\mathrm{HNO}_{3}$ concentration. The behaviour of the distribution values and the separation factors for the three $\mathrm{Ln}$ is quite similar in regard to the feed nitric acid.

The two extracting systems showed selectivity toward heavy Ln in regard to the light $L$. The change in feed acidity had an effect on the selectivity factor of $\mathrm{Yb} / \mathrm{La}$ where the increase in acid concentration from $0.001 \mathrm{M}$ to $3 \mathrm{M}$ leads to an increase in the selectivity of LI and LII from 1750 to 3900 and from 2900 to 5400, respectively. However, no significant change has been observed for the selectivity factors of $\mathrm{Yb} / \mathrm{Eu}$ and $\mathrm{Eu} / \mathrm{La}$ upon changing the acidity. The trend in extraction performance seems to be proportional to the lanthanide contraction $(\mathrm{La} \ll \mathrm{Eu}<\mathrm{Yb})$ and related to the charge density of the metal ion showing a higher selectivity for the heavy Ln. Based on the HSAB theory, hard donor extractants strongly bind the cations of high charge densities. $O$-donor extractants including DGA are usually considered as hard ligands, ${ }^{36}$ therefore they form more stable complexes with heavy (Yb) than with light (La) lanthanides.

Otherwise, the necessary energy required to dehydrate the $\mathrm{Ln}$ is improved with increasing atomic number and decreasing ionic radii. ${ }^{37}$ Thereby, the selectivity for heavy Ln suggests that the coordination ability of CR4-TZ-DODGA and C4-TZ-DODGA toward Ln is predominant over their dehydration energies. However, other factors such as the geometry of the coordination site and the hydrophobicity of the extracted complexes have to be considered. ${ }^{38}$

a) CR4-TZ-DODGA

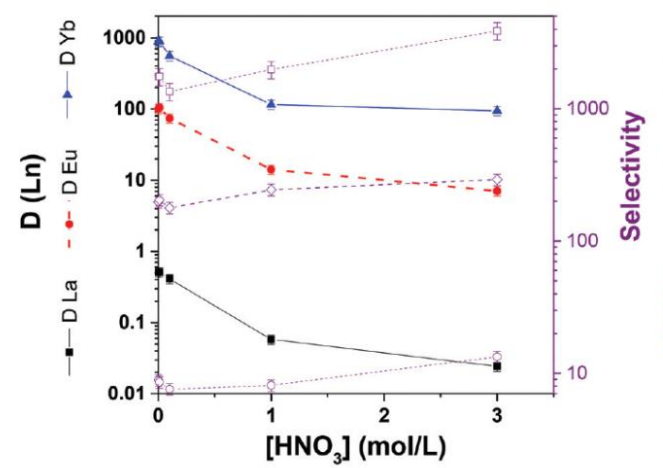

b) C4-TZ-DODGA

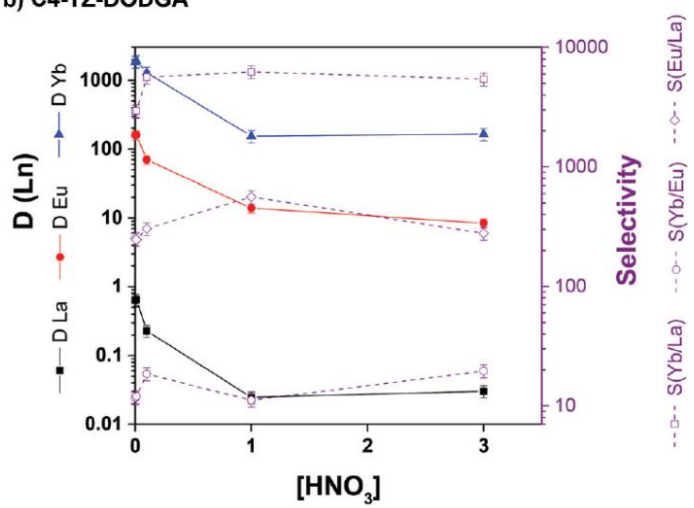

Fig. 3 Effect of nitric acid concentration on the distribution ratios (solid lines) of $\mathrm{La}^{3+}$ (squares); Eu ${ }^{3+}$ (circles) and $\mathrm{Yb}^{3+}$ (triangles), and the selectivity factors (dashed lines) for (a) CR4-TZ-DODGA and (b) C4-TZ-DODGA. Aqueous phase: $2 \mathrm{mM}$ of $\operatorname{Ln}\left(\mathrm{NO}_{3}\right)_{3}$ in $\mathrm{HNO}_{3}$. Extracting phase: [ligand] = 2 mM in [EOPip]NTf2/octanol (9/1). 
Therefore, the complexation depends largely on the ionic radius of the metal ion. The rigidity of the macrocycle also appears to have an influence on the selectivity and complexation of metal ions when the extraction results of the two ligands are compared.

The more rigid macrocyclic ligand CR4-TZ-DODGA based on the resorcin[4]arene cavitand is slightly less efficient than the C4-TZ-DODGA type calix[4]arene.

Based on a solvating mechanism due to the neutral nature of the ligand, and thanks to the salting out effect of the nitrate ions, an increase in the extraction ability of an extractant is thus parallel to the increase in the nitric acid concentration. Wonderingly this is not the case, the data suggest that the transfer of lanthanides into the IL phase did not involve any co-extraction of $\mathrm{NO}_{3}{ }^{-}$as already observed for TODGA in the IL system ${ }^{14}$ and that the $\mathrm{H}^{+}$ions compete with the metal ions and hence the distribution ratio of $\mathrm{Ln}$ decreases with increasing feed acidity. ${ }^{29}$ This behaviour suggests that the extraction follows an ion exchange mechanism throughout the acidity range.

In our study from the analysis of the aqueous phase, it appears that the ion exchange mechanism is probably not the driving force of the extraction. In order to evaluate the potential partition of the ligand and/or the IL in the aqueous phase, a sample of a $0.01 \mathrm{M} \mathrm{HNO}_{3}$ aqueous phase containing $0.66 \mathrm{mM}$ of lanthanum was brought into contact with $2.64 \mathrm{mM}$ of LII dissolved in [EOPip]NTf2/octanol (9/1) for one hour and then analysed by NMR spectroscopy. The absence of signals corresponding to the IL cation in the ${ }^{1} \mathrm{H}$ NMR analysis of the aqueous phase indicates that no cation exchange occurred in the mechanism of this IL-based extraction. Also, the exchange of the NTf2 anion into the aqueous phase appears negligible by following the ${ }^{19} \mathrm{~F}$ nucleus. Therefore, at low acidity, the mechanism of the extraction pathway appears to be not consistent with the anion or cation exchange mechanism.

This suggests the fact that the extraction mechanism of this ligand/IL-based extraction is more likely to be solvation which is in agreement with the behaviour of neutral extractants in [EOPip]NTf2. ${ }^{18}$ The solvation mechanism is usually reported for the extraction with neutral extractants in long alkyl chain ionic liquids. ${ }^{39,40}$ In view of the above observations it is difficult to eliminate the possibility of one or the other of the mechanisms. The extraction can proceed through a combination of an ion exchange mechanism (the $D$ values decrease with the increase of the acidity) and neutral complex partitioning (no evidence of anion and cation exchange). The balance of the extraction pathway is probably driven by the acidity of feed solution.

The possibility of mixed partitioning mode has been described in the literature. ${ }^{41}$

After extraction, we did not observe a variation of the $\mathrm{pH}$. Acid extraction by the neutral compound is considered negligible. ${ }^{28} \mathrm{However}$, with TODGA, some adducts can be formed at high acidity between the diglycolamide and nitric acid. ${ }^{42}$ Also, considering an ion exchange mechanism, a competitive reaction can also occur due to the influence of $\mathrm{H}^{+}$. No concrete evidence of acid extraction was observed which does not allow to discriminate one or the other of the mechanism.

The various findings suggest that the lanthanides can be extracted via a combination of the ion pair complex formation and ion-exchange mechanism. By considering the solvation mechanism as the mechanism involved in the extraction by neutral extractants, the equation of the solvation extraction was written as eqn $(1)^{39,40}$

$\mathrm{M}_{\mathrm{aq}}^{3+}+3 \mathrm{NO}_{3}^{-} \mathrm{aq}+x \overline{\mathrm{L}}_{\mathrm{IL}} \leftrightarrow \overline{\mathrm{M}\left(\mathrm{NO}_{3}\right)_{3} \cdot x \mathrm{~L}} \mathrm{IL}$,

where $\mathrm{M}$ represents the $\mathrm{Ln}, \mathrm{L}^{-}$IL represents the neutral extractant (CR4-TZ-DODGA or C4-TZ-DODGA), $\overline{\mathrm{M}\left(\mathrm{NO}_{3}\right)_{3} \cdot \mathrm{L}}$ represents the metal-ligand complex in the IL phase. The overbar refers to the transferred species to the IL phase, and the absence of the overbar denotes aqueous species. Considering that the extraction of Ln by DGA ligands occurs by a solvation mechanism, the electroneutrality of the system must be ensured by a concomitant co-extraction of nitrate counter ions. Indeed, no significant change of the extraction trend with increasing acidity seems to be observed at lower acidities.

Also, the extraction profile with a moderate decrease of the $D$ values with an increase of the feed acidity suggests that the extracted species does not contain nitrate species and an ionexchange mechanism for the extraction can be considered and the extraction equilibrium in IL medium can be written as eqn $(2)^{41}$

$\mathrm{M}_{\mathrm{aq}}^{3+}+3 \overline{\left[\text { EOPip }^{+}\right.}{ }_{\mathrm{IL}}+x \mathrm{~L}_{\mathrm{IL}} \leftrightarrow{\overline{\mathrm{ML}_{x}{ }^{3+}}}_{\mathrm{IL}}+3[\text { EOPip }]_{\mathrm{aq}}^{+}$.

\section{Effect of ligand concentration}

In order to investigate the influence of the ligand concentration on the extraction efficiency, we then performed different extraction experiments with each individual metal at $0.66 \mathrm{mM}$ and at its optimal acidity, i.e. $0.01 \mathrm{M}\left[\mathrm{HNO}_{3}\right]$, with different concentrations of ligands. The ligand concentration range was chosen between 0.165 and $2.64 \mathrm{mM}$ which corresponds to a ligand over individual metal ratio ranging between 0.25 and 4. The solvent extraction data of $\mathrm{La}(\mathrm{III}), \mathrm{Eu}(\mathrm{III})$ and $\mathrm{Yb}$ (III) from $0.01 \mathrm{M} \mathrm{HNO}_{3}$ using various concentrations of CR4-TZDODGA and C4-TZ-DODGA ligands are summarized in Fig. 4 and Table SI-1 (see the ESI).

No significant extraction of La and Eu was observed at low concentrations of extractants, where their extraction performances were increased with the increase of the ligand concentration.

The extraction of Yb with CR4-TZ-DODGA and C4-TZ-DODGA reached higher D values than for La and Eu under comparable conditions. The slightly different efficiency of the two ligands LI and LII can be attributed to the difference in the rigidity of the macrocyclic platform. The rigid conformation of CR4-TZ-DODGA leaves little room for rearrangement of the ligating groups which leads to slightly lower values for the distribution coefficient. The pre-orientation of the coordinating sites is probably more favourable in the ligand LII. 
According to the results previously obtained in a comparative study involving an organic solvent, ${ }^{30}$ it appears that the IL medium is preferable to the classical solvent in terms of the performances of the ligand (distribution coefficient and separating factor). In most of the examples described in the literature, remarkable extraction efficiencies are obtained when the ligand is dissolved in ILs in comparison with common organic solvents.

The same trend for the selectivity profile of $\mathrm{LI}$ toward $\mathrm{Yb}$ has been observed in toluene/octanol and [EOPip][NTf2]/octanol.

a) CR4-TZ-DODGA

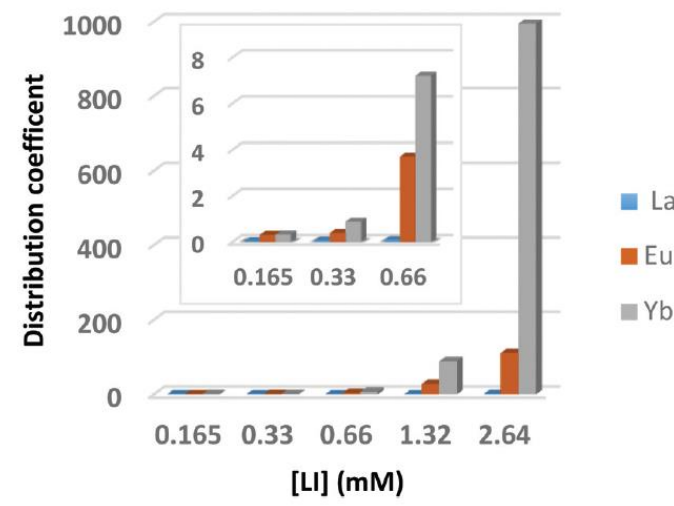

b) C4-TZ-DODGA

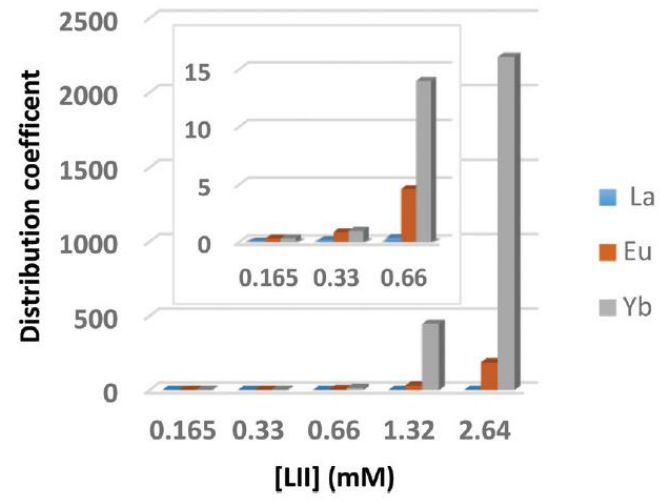

Fig. 4 Evolution of the extraction efficiency as a function of the extractant concentration LI (a) and LII (b) in [EOPip]NTf2/octanol (9/1) for the individual lanthanides $\left(\mathrm{La}^{3+}, \mathrm{Eu}^{3+}\right.$, and $\left.\mathrm{Yb}^{3+}\right),[\mathrm{Ln} 3+]=0.66 \mathrm{mM}$ in $0.01 \mathrm{M} \mathrm{HNO}_{3}$.

The $\mathrm{D}$ values obtained with $5 \mathrm{mM} \mathrm{LI}$ in toluene for $\mathrm{La}(\mathrm{III}), \mathrm{Eu}(\mathrm{III})$ and $\mathrm{Yb}(\mathrm{III})$ were approximately $0.3,5$, and 140, respectively, where in the ionic liquid the $D$ values for the same elements were about $0.5,112$, and 995 for about two times lower concentration (2.64 mM). This quite interesting feature of the ionic liquid comes from the fact that a much lower concentration of the ligand can be used to reach the same or greater efficiency as in the classical solvents.

These differences can be attributed to a better organization of the ligand in the ionic liquid solvent known to be structuring a better solvation of the metal species in the ionic liquid (higher dielectric constant) or a different supramolecular organization. ${ }^{20}$ Therefore, the IL system can be considered as an alternative to toluene for the extraction of lanthanides by the macrocyclic ligand bearing diglycolamide used in this study.

In order to investigate the stoichiometry of the complex(es) involved in the IL phase by the ligand, single-metal ion extractions were performed at $0.01 \mathrm{M}^{2}\left[\mathrm{HNO}_{3}\right]$ and at different concentrations for both ligands. At this acidity we suppose that the extraction mechanism is mainly due to the ion pair complex formation as described by eqn (1). Based on the postulated equilibrium and neutral complex formation, the extraction constant, Kex, can be represented as eqn (3):

$$
K_{\mathrm{ex}}=\frac{\left[\overline{\mathrm{M}\left(\mathrm{NO}_{3}\right)_{3} \cdot \mathrm{L}}\right]_{\mathrm{IL}}}{\left[\mathrm{M}^{3+}\right]_{\mathrm{aq}} \times\left[\mathrm{NO}_{3}^{-}\right]_{\mathrm{aq}}^{3} \times \overline{[\mathrm{L}]_{\text {free }}}} .
$$

Therefore, by substituting the $D$ value in eqn (3), the extraction constant is:

$$
K_{\text {ex }}=\frac{D_{\mathrm{M}}}{\left[\mathrm{NO}_{3}^{-}\right]_{\mathrm{aq}}^{3} \times \overline{\left[\mathrm{L}_{\mathrm{IL}}\right]_{\text {free }}}}
$$

From eqn (4), the $\left[\mathrm{NO}_{3}{ }^{-}\right]$can be regarded as constant, ${ }^{43}$ and therefore the conditional extraction constant $\mathrm{K}^{\prime}$ ex can be given as:

$$
K_{\mathrm{ex}}^{\prime}=\frac{D_{\mathrm{M}}}{\left[\mathrm{L}_{\mathrm{IL}}\right]_{\text {free }}} \text {. }
$$

Eqn (5) can be rearranged as

$$
\log D_{\mathrm{M}}=\log K_{\text {ex }}^{\prime}+\log \left[\mathrm{L}_{\mathrm{LL}}\right]_{\text {free }}
$$

The stoichiometry of the $\mathrm{Ln}^{3+}$ nature of the extracted species was determined at $0.01 \mathrm{M} \mathrm{HNO}_{3}$ from the $\log \mathrm{D}_{\mathrm{Ln}} \mathrm{Vs}$. log $[\mathrm{L}]_{\text {free }}$ plots obtained by varying the ligand concentration (Fig. 5).

The data of the $\log D_{\llcorner n}$ Vs. $\log \left[L_{L I}\right]_{\text {free }}$ plots and the conditional extraction constant values are listed in Table 1 . The log $K^{\prime}$ ex of the two ligands can be calculated from the intercepts of the straight lines obtained by plotting the $\log D_{L n} V s . \log \left[L_{I L}\right]_{\text {free }}$ at a constant nitric acid concentration $\left(0.01 \mathrm{M} \mathrm{HNO}_{3}\right)$. A similar trend and value have been obtained for both ligands. 


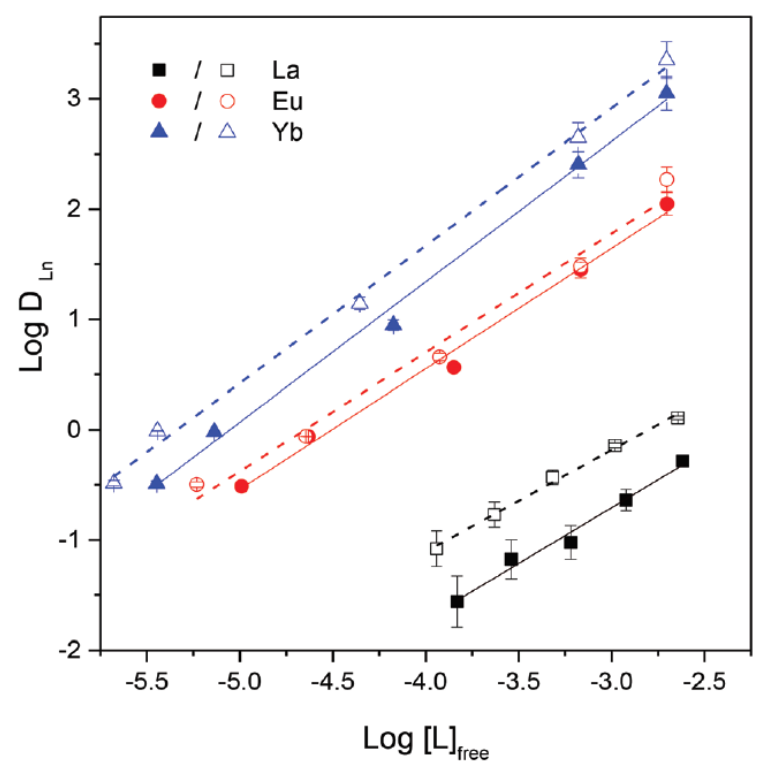

Fig. 5 Slope analysis of lanthanide extraction as a function of free ligand concentration for LI (closed symbols and solid lines) or LII (open symbols and dashed lines). Aqueous phase: $0.66 \mathrm{mM}$ of individual $\operatorname{Ln}\left(\mathrm{NO}_{3}\right)_{3}$ in $0.01 \mathrm{M} \mathrm{HNO}_{3} \mathrm{La}^{3+}$ (squares); $\mathrm{Eu}^{3+}$ (circles) or $\mathrm{Yb}^{3+}$ (triangles).

Extracting phase: [ligand] $=1.65-2.64 \mathrm{mM}$ in [EOPip]NTf2/octanol $(9 / 1) \cdot \log \left(D_{\mathrm{La}}\right)=f\left(\log [\right.$ CR4-DODGA] free $): y=1.014( \pm 0.075) x+2.333( \pm 0.247) R^{2}=0.983$; $\log \left(D_{\text {Eu }}\right)=f\left(\log [C R 4-D O D G A]_{\text {free }}\right): y=1.093( \pm 0.056) x+4.926( \pm 0.224), R^{2}=0.992 ; \log \left(D_{\text {Yb }}\right)=f\left(\log [C R 4-D O D G A]_{\text {free }}\right): y=1.274( \pm 0.049) x+6.437( \pm 0.210), R^{2}=$ 0.995. $\log \left(D_{\text {La }}\right)=f\left(\log [C 4-D O D G A]_{\text {free }}\right): y=0.924( \pm 0.039) x+2.589( \pm 0.129), R^{2}=0.995 ; \log \left(D_{E u}\right)=f\left(\log [C 4-D O D G A]_{\text {rree }}\right): y=1.078( \pm 0.078) x+5.013( \pm 0.316), R^{2}$ $=0.984 ; \log \left(D_{\mathrm{Yb}}\right)=f(\log [C 4-D O D G A]$ free $): y=1.248( \pm 0.038) x+6.661( \pm 0.170), R^{2}=0.997$.

Table 1 Slopes and log $\mathrm{K}^{\prime}$ ex for the complexation of $\mathrm{LI}$ and $\mathrm{LIl}$ with $\mathrm{Ln}^{3+}, 0.66 \mathrm{mM}$ of each individual $\mathrm{Ln}\left(\mathrm{NO}_{3}\right)_{3}$ in $0.01 \mathrm{M} \mathrm{HNO}_{3}$

\begin{tabular}{|c|c|c|c|c|}
\hline & \multicolumn{2}{|l|}{ LI } & \multicolumn{2}{|l|}{ LII } \\
\hline & Slope & $\log K_{\mathrm{ex}}^{\prime}$ & Slope & $\log K_{\mathrm{ex}}^{\prime}$ \\
\hline $\mathrm{La}$ & 1.014 & 2.333 & 0.924 & 2.589 \\
\hline $\mathrm{Eu}$ & 1.093 & 4.926 & 1.078 & 5.013 \\
\hline $\mathrm{Yb}$ & 1.274 & 6.437 & 1.248 & 6.661 \\
\hline
\end{tabular}

The plot of $\log D_{L n}$ vs. log $[L]_{\text {free }}$ yields slopes of approximately 1 for both ligands. The results suggest that the stoichiometry of the predominantly extracted species is $1: 1$ (metal/ ligand) for both extractants which is consistent with the solvent extraction studies reported in the literature for DGAfunctionalized calix[4]arene ligands. ${ }^{44}$

Despite their different rigidities, a similar stoichiometry has been obtained for the two macrocycles, CR4-TZ-DODGA and C4-TZ-DODGA. The rigidity of the platform or the steric environment of the ligating DGA in regard to the formation of the complexes, even if different, has no influence on the extraction results.

However, different stoichiometries have been observed for CR4-TZ-DODGA in the toluene system, where $1: 2 \mathrm{ML}$ complexing species have been obtained for $\mathrm{La}^{3+}, \mathrm{Eu}^{3+}$ or $\mathrm{Yb}^{3+} .30$ It is postulated that, by changing the diluent and the acidity, different complexing species between the same metal and the same ligand can be observed. ${ }^{26,29,45}$ This can also be due to a different supramolecular organization of the ligand in the ionic liquid, based probably on the interactions of the DGA and/or the triazole moieties with the ionic liquids.

\section{Determination of thermodynamic parameters}

The metal ion extraction data at varying temperatures (between 25 and $45^{\circ} \mathrm{C}$ ) were used to estimate the thermodynamic parameters, which were subsequently used to provide further trends regarding the complexation of $\mathrm{Ln}$ with both ligands. The effect of temperature on the extraction of $\mathrm{Ln}$ from a $0.01 \mathrm{M} \mathrm{HNO}_{3}$ aqueous solution by $1 \mathrm{mM}$ CR4-TZ-DODGA or $1 \mathrm{mM}$ C4-TZ-DODGA into [EOPip]NTf2/octanol (9/1 $\mathrm{v} / \mathrm{v}$ ) was studied. As usual, the observed increase in temperature leads to a decrease in the extraction efficiency. The decrease of the distribution ratio for $\mathrm{Ln}(\mathrm{III})$ with increasing temperature indicates the extraction process to be exothermic (Fig. 6).

The change in the enthalpy $(\Delta \mathrm{H})$ can be calculated using the Van't Hoff relationship (7), where $\mathrm{R}$ is the gas constant:

$\Delta H=-2.303 R \Delta \log D / \Delta(1 / T)$.

A plot of log $D$ versus $1 / T$ gives straight lines of slopes of $-\Delta H / 2.303 R$ as shown in Fig. 6 while the Gibb's free energy can be calculated from the Gibbs's Helmholtz equation: 
And the change in entropy $(\Delta S)$ at a particular temperature can be calculated using the equation:

$\Delta G=\Delta H-T \Delta S$.

The thermodynamic parameters $(\Delta \mathrm{H}, \Delta \mathrm{S}$, and $\Delta \mathrm{G})$ calculated for the two extraction systems are summarized in Table 2.

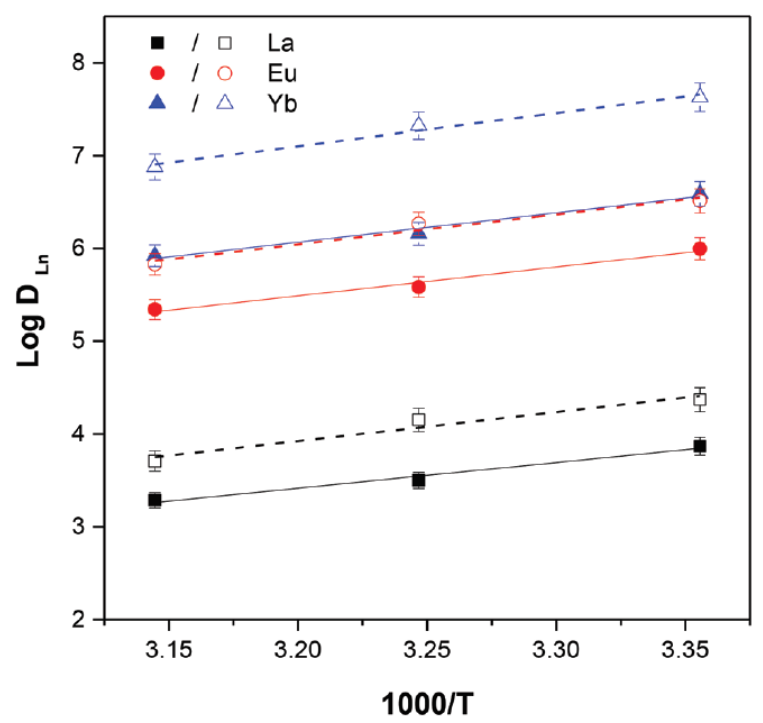

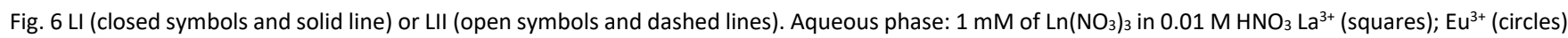
or $\mathrm{Yb}^{3+}$ (triangles). Extracting phase: [ligand] $=1 \mathrm{mM}$ in [EOPip]NTf2/octanol $(9 / 1) \cdot \log \left(D\right.$ La-LI) $=f(1000 / \mathrm{T}): y=2.774( \pm 0.373) x-5.460( \pm 1.212), \mathrm{R}^{2}=0.982$; $\log (D$ Eu$-\mathrm{LI})=f(1000 / \mathrm{T}): \mathrm{y}=3.115( \pm 0.411) x-4.479( \pm 1.337), \mathrm{R}^{2}=0.983 ; \log (D \mathrm{Yb}-\mathrm{LI})=\mathrm{f}(1000 / \mathrm{T}): \mathrm{y}=3.176( \pm 0.470) \mathrm{x}-4.094( \pm 1.527), \mathrm{R}^{2}=0.978 . \log (D \mathrm{La}-$ LII $)=f(1000 / T): y=3.129( \pm 0.685) x-6.091( \pm 2.225), R^{2}=0.954 ; \log (D$ Eu-LII $)=f(1000 / T): y=3.236( \pm 0.587) x-4.309( \pm 1.909), R^{2}=0.968 ; \log (D$ Yb-LII $)=f$ $(1000 / T): y=3.550( \pm 0.451) x-4.256( \pm 1.467), R^{2}=0.984$

Table 2 Thermodynamic parameters $(\Delta \mathrm{H}, \Delta \mathrm{S}$, and $\Delta \mathrm{G})$ for the extraction of $\mathrm{La}(\mathrm{III}), \mathrm{Eu}(\mathrm{III})$ and $\mathrm{Yb}$ (III) at $298 \mathrm{~K}$

\begin{tabular}{llllll}
\hline & & Slope & $\Delta H\left(\mathrm{~kJ} \mathrm{~mol}^{-1}\right)$ & $\Delta S\left(\mathrm{~J} \mathrm{~K}^{-1} \mathrm{~mol}^{-1}\right)$ & $\Delta G\left(\mathrm{~kJ} \mathrm{~mol}^{-1}\right)$ \\
\hline LI & LaL & 2.77 & $-53(7)$ & $-134(19)$ & $-13(1)$ \\
& EuL & 3.11 & $-59(8)$ & $-106(22)$ & $-28(1)$ \\
& YbL & 3.18 & $-61(9)$ & $-81(26)$ & $-37(1)$ \\
LII & LaL & 3.13 & $-60(13)$ & $-152(42)$ & $-15(1)$ \\
& EuL & 3.24 & $-61(11)$ & $-112(32)$ & $-29(2)$ \\
& YbL & 3.55 & $-68(9)$ & $-101(26)$ & $-38(1)$
\end{tabular}

Aqueous phase: $1 \mathrm{mM} \operatorname{Ln}(\mathrm{NO} 3) 3$ in $0.01 \mathrm{M}$ HNO3. Extracting phase: [ligand] = $1 \mathrm{mM}$ in [EOPip]NTf2/octanol (9/1).

The overall enthalpy change depends on several contributing factors, such as (i) dehydration of metal ions ( $\Delta \mathrm{H} 1$ ), (ii) formation of neutral extracted species $(\Delta \mathrm{H} 2)$, and (iii) dissolution of the metal complex in the organic phase $(\Delta \mathrm{H} 3)$. The negative $\Delta \mathrm{H}$ values suggest that the complexations of $\mathrm{Ln}$ by the extractant molecules are exothermic (Table 2). The configuration of the calix[4]arenes may also play a role in the complexation which is linked to entropy changes. Negative entropy changes $(-\Delta S)$ can be attributed to the loss of rotational entropy of the ligands during complexation. ${ }^{26}$ Due to a more rigid preorganization of the ligating groups, the $\Delta S$ of complex formation is less negative for LI than LII.

Indeed, the less negative values were found for the less extracted $L$. The changes in the Gibbs free energy $(-\Delta G)$ for the both ligands follow the order: $\Delta G(Y b)>\Delta G(E u)>\Delta G(L a)$, which means that the extraction of $\mathrm{Yb}$ is energetically more favoured than the extraction of Eu and La, respectively. The negative values of $\Delta \mathrm{G}$ at room temperature indicate that the extraction reactions are spontaneous.

Permanent magnets

Extraction experiments. Taking into account the performances and the potential of CR4-TZ-DODGA and C4-TZ-DODGA in the IL phase for the extraction of Ln, the efficiency and the selectivity of these systems were then studied toward the extraction of $\mathrm{Nd}$ and $\mathrm{Dy}$ over Fe and $B$ contained in a simulated leaching solution of permanent magnets. The ligands at $1 \mathrm{mM}$ in [EOPip]NTf2/octanol (9/1 v/v) were brought into contact with a mixture of the targeted metals at a total concentration of $2 \mathrm{mM}$ into $0.01 \mathrm{M}$ nitric acid. The extraction data are presented in Table 3.

The results showed that the ligands extract, mostly $\mathrm{Nd}(\mathrm{III})$ and $\mathrm{Dy}(\mathrm{III})$, and no significant extraction was observed for Fe and $\mathrm{B}$. This suggests that CR4-TZ-DODGA and C4-TZ-DODGA are appropriate ligands for the selective recovery of Ln from permanent magnets in regard to competitive ions especially iron, which is the main competitive ion in the nitric acid leaching solution.

Stripping and recovery of $\mathrm{Ln}$. After the successful extraction of Dy and $\mathrm{Nd}$ from the leaching solution of the permanent magnets, another set of experiments were then carried out in order to recover the extracted target metals. Therefore, the ionic liquid phase, already loaded 
with these two metals, was then stripped with ammonium carbonate, ammonium oxalate and deionized water. The recovered percentages are presented in Table 4.

Among the three tested solutions, ammonium carbonate displays promising results when the stripping was performed with a ratio of aqueous over organic phase $\mathrm{A} / \mathrm{O}=1$. As shown in Table 4, Dy and $\mathrm{Nd}$ can be mainly recovered after stripping the organic phase with ammonium carbonate. By increasing the ratio $\mathrm{A} / \mathrm{O}$ or performing the successive stripping step, the totality of the Ln extracted is expected to be recovered.

Table 3 Distribution value of Nd/Dy/Fe/B cations from $0.01 \mathrm{M} \mathrm{HNO}_{3}$ aqueous solution into [EOPip]NTf2 containing 1 mM CR4-TZ-DODGA / C4-TZ-DODGA at $25^{\circ} \mathrm{C}$

\begin{tabular}{llllll}
\hline & $D(\mathrm{Fe})$ & $D(\mathrm{~B})$ & $D(\mathrm{Nd})$ & $D(\mathrm{Dy})$ & $S(\mathrm{Dy} / \mathrm{Nd})$ \\
\hline LI & $<0.01$ & 0.01 & 13 & 2264 & 167 \\
LII & $<0.01$ & 0.02 & 72 & 6794 & 94
\end{tabular}

Aqueous phase: $2 \mathrm{mM}$ of metals: $70 \% \mathrm{Fe}, 10 \% \mathrm{Dy}, 10 \% \mathrm{Nd}, 10 \% \mathrm{~B}$ in $0.01 \mathrm{M} \mathrm{HNO}_{3}$. Extracting phase: [ligand] = $1 \mathrm{mM}$ in [EOPip]NTf2/ octanol (9/1).

Table 4 Recovery of $\mathrm{Nd}$ and Dy from an extracting phase (1 mM ligand in [EOPip]NTf2/octanol (9/1)) by aqueous solution (ratio of the aqueous over organic phase $\mathrm{A} / \mathrm{O}=1)$

\begin{tabular}{llll}
\hline & Stripping solution & Dy recovery $(\%)$ & Nd recovery $(\%)$ \\
\hline LI & {$\left[(\mathrm{NH} 4)_{2} \mathrm{C}_{2} \mathrm{O}_{4}\right]\left(1 \mathrm{~mol} \mathrm{~L}^{-1}\right)$} & 20 & 17 \\
& {$\left[(\mathrm{NH} 4)_{2} \mathrm{CO}_{3}\right]\left(1 \mathrm{~mol} \mathrm{~L}^{-1}\right)$} & 51 & 51 \\
& $\mathrm{H}_{2} \mathrm{O}$ & 1 & 0 \\
LII & {$\left[(\mathrm{NH} 4)_{2} \mathrm{C}_{2} \mathrm{O}_{4}\right]\left(1 \mathrm{~mol} \mathrm{~L}^{-1}\right)$} & 42 & 33 \\
& {$\left[(\mathrm{NH} 4)_{2} \mathrm{CO}_{3}\right]\left(1 \mathrm{~mol} \mathrm{~L}^{-1}\right)$} & 59 & 57 \\
& $\mathrm{H}_{2} \mathrm{O}$ & 1 & 0
\end{tabular}

\section{Experimental}

\section{General considerations}

Chemicals (analytically pure) were purchased from Sigma- Aldrich, Eburon Organic or Alfa Aesar and were used without further purification. Anhydrous solvents were purchased from Acros $\left(\right.$ AcroSeal $\left.^{\circledR}\right)$. Reactions were monitored by thin layer chromatography (Merck TLC Silica Gel 60 F254).

Flash chromatography was performed using a combiflash Agilent Intelliflash 971-FP. NMR analyses were performed on a Bruker 400 ultrashield VS spectrometer. Displacements are reported in ppm using the solvent (CDCl3: 7.26 ppm 1H; 77.16 ppm 13C) as an internal reference. Metal concentrationswere determined using a spectro ARCOS ICPAES spectrometer. Fourier transform infrared (FTIR) measurements were performed on a PerkinElmer Spectrum 100 instrument in ATR (Attenuated Total Reflection) mode. The wavenumber range was from $400 \mathrm{~cm}^{-1}$ to $4000 \mathrm{~cm}^{-1}$. The beam resolution was $4 \mathrm{~cm}^{-1}$. Background acquisition was done before measurement. ESI-MS was performed on a microTOF-Q apparatus.

\section{Synthesis}

\section{Compound 1.}

Compound 1 was synthesized by substituting the bromine group in bromopropylamine hydrobromide with the sodium azide group using sodium azide in water as described in the literature. ${ }^{46}$

${ }^{1} \mathrm{H}$ NMR (400 MHz, CDCl3) $\delta[\mathrm{ppm}]: 1.17(\mathrm{~s}, 2 \mathrm{H}, \mathrm{NH} 2), 1.7(\mathrm{p}, 2 \mathrm{H}, \mathrm{CH} 2-\mathrm{CH} 2-\mathrm{CH} 2), 2.77(\mathrm{t}, 2 \mathrm{H}, \mathrm{J}=6.8 \mathrm{~Hz},-\mathrm{CH} 2-\mathrm{N} 3), 3.35(\mathrm{t}, 2 \mathrm{H}, \mathrm{J}=6.8 \mathrm{~Hz}$, $\mathrm{NH} 2-\mathrm{CH} 2)$.

${ }^{13} \mathrm{CNMR}(100 \mathrm{MHz}, \mathrm{CDCl} 3) \delta[\mathrm{ppm}]: 32.5,39.3$, and 49.1 .

Compound 2.

Compound 2 was synthesized by an open ring reaction of diglycolic anhydride with octylamine as the procedure described in the literature. ${ }^{33,47}$

${ }^{1} \mathrm{H} \mathrm{NMR}(400 \mathrm{MHz}, \mathrm{CDCl} 3) \delta[\mathrm{ppm}]: 0.89(\mathrm{~m}, 6 \mathrm{H}, \mathrm{CH} 2-\mathrm{CH} 3), 1.28(\mathrm{~m}, 2 \mathrm{H}, \mathrm{NCH} 2-\mathrm{CH} 2-(\mathrm{CH} 2) 5-\mathrm{CH} 3), 1.56(\mathrm{~m}, 4 \mathrm{H},(\mathrm{NH}-\mathrm{CH} 2-\mathrm{CH} 2-\mathrm{CH} 2))$, 3.10 (t, 2H, $7.6 \mathrm{~Hz}, \mathrm{~N}-\mathrm{CH} 2-)$, 3.32 (t, 2H, $7.6 \mathrm{~Hz}, \mathrm{~N}-\mathrm{CH} 2-), 4.22$ (s, 2H, CO-CH2-CO), 4.44 (s, 2H, CO-CH2-CO).

${ }^{13} \mathrm{C}$ NMR $(100 \mathrm{MHz}, \mathrm{CDCl} 3) \delta[\mathrm{ppm}]: 14.1,22.6,22.7,26.8,26.9,27.4,28.6,29.2,29.3,29.5,31.8,31.9,46.9(\mathrm{~N}-\mathrm{CH} 2), 71.2(\mathrm{CO}-\mathrm{CH} 2-\mathrm{O})$, $73.0(\mathrm{O}-\mathrm{CH} 2-\mathrm{CO}), 170.6(\mathrm{C}=\mathrm{O})$, and $171.8(\mathrm{C}=\mathrm{O})$.

\section{Compound 3.}

$0.5 \mathrm{~g}$ of compound 2 2-(2-(dioctylamino)-2-oxoethoxy) acetic acid DODGA (1.21 mmol) and $0.2 \mathrm{~g}$ of hydroxybenzotriazole HOBt (1.33 mmol) were poured into $30 \mathrm{~mL}$ chloroform at $0{ }^{\circ} \mathrm{C}$. To the obtained suspension, $0.275 \mathrm{~g}$ of dicyclohexylcarbodiimide DCC (1.33 mmol) was added 
and the obtained suspension was stirred for 30 minutes at room temperature, after which $0.28 \mathrm{~g}$ of compound 1 ( $2.9 \mathrm{mmol})$ were added and the resulting suspension was stirred for two days after which the precipitates were removed by filtration. The obtained crude product is purified further through silica gel column chromatography using dichloromethane/methanol $5 \%$ as the eluent, to afford 3 as a pure compound $(0.79 \mathrm{~g}, 82.5 \%)$.

${ }^{1} \mathrm{H}$ NMR $(400 \mathrm{MHz}, \mathrm{CDCl} 3) \delta[\mathrm{ppm}]: 0.91(\mathrm{~m}, 6 \mathrm{H},(\mathrm{CH} 2-\mathrm{CH} 3)), 1.30(\mathrm{~m}, 2 \mathrm{H}, \mathrm{N}-\mathrm{CH} 2-\mathrm{CH} 2-(\mathrm{CH} 2) 5-\mathrm{CH} 3), 1.55(\mathrm{~m}, 4 \mathrm{H},(\mathrm{NH}-\mathrm{CH} 2-\mathrm{CH} 2-\mathrm{CH} 2))$, $1.85(\mathrm{~m}, 2 \mathrm{H}, \mathrm{NH}-\mathrm{CH} 2-\mathrm{CH} 2-\mathrm{CH} 2-\mathrm{N} 3), 3.10(\mathrm{t}, 2 \mathrm{H}, 7.6 \mathrm{~Hz}, \mathrm{~N}-\mathrm{CH} 2-), 3.32(\mathrm{t}, 2 \mathrm{H}, 7.6 \mathrm{~Hz}, \mathrm{~N}-\mathrm{CH} 2-), 3.38(\mathrm{~m}, 4 \mathrm{H}, \mathrm{NH}-\mathrm{CH} 2-\mathrm{CH} 2-\mathrm{CH} 2-\mathrm{N} 3$ and $\mathrm{NH}-\mathrm{CH} 2-\mathrm{CH} 2-\mathrm{CH} 2-\mathrm{N} 3$ ), 4.09 (s, 2H, CO-CH2-CO), 4.26 (s, 2H, CO-CH2-CO), 8.15(s, 1H, NH-CvO).

${ }^{13} \mathrm{C}$ NMR $(100 \mathrm{MHz}, \mathrm{CDCl} 3) \delta$ [ppm]: 14.0, 14.1, 22.6, 22.7, 26.9, 27.0, 27.6(NH-CH2), 28.8, 28.9, 29.1, 29.2, 29.3, 29.4, 31.7, 31.8, 36.3, $46.3,46.8,49.2,69.8,72.3,168.3(\mathrm{CO}-\mathrm{NH}), 169.8(\mathrm{CO}-\mathrm{N})$.

Compound 4.

The reaction of p-tert-butylcalix[4]arene with a mild base followed by the addition of a molar excess of propargyl bromide yielded the tetraalkyne molecule cone-tetrapropargyl p-tertbutylcalix[4]arene as described in the literature. ${ }^{32}$ The synthesis was carried out in the following manner: $3 \mathrm{~g}$ of tertbutyl- calix[4]arene $(4.6 \mathrm{mmol})$ and $2.56 \mathrm{~g}$ potassium carbonate $(18.5 \mathrm{mmol})$ were mixed together in dry acetonitrile $(50 \mathrm{~mL})$ for about 30 minutes, after which $4.4 \mathrm{~g}$ of propargyl bromide $(37 \mathrm{mmol})$ was added and the resulting solution was refluxed at $80{ }^{\circ} \mathrm{C}$ for two days. Finally, the precipitates were removed by filtration where the solvent and propargyl bromide were evaporated under reduced pressure to afford $3.4 \mathrm{~g}$ of $4(91.9 \%)$.

${ }^{1} \mathrm{H}$ NMR (400 MHz, CDCl3) $\delta$ [ppm]: $1.10(\mathrm{~m}, 36 \mathrm{H}, \mathrm{CH} 3), 2.50$ (s, 4H, CuCH), 3.20 (d, $4 \mathrm{H}, \mathrm{J}=12.8 \mathrm{~Hz}$, inner Ar-CH2-Ar), $4.64(\mathrm{~d}, 4 \mathrm{H}, \mathrm{J}=12.8$ $\mathrm{Hz}$, outer $\mathrm{Ar}-\mathrm{CH} 2-\mathrm{Ar}), 4.83$ (s, 8H, O-CH2), 6.8 (s, $8 \mathrm{H}, \mathrm{ArH})$.

${ }^{13} \mathrm{C} N M R(100 \mathrm{MHz}, \mathrm{CDCl} 3) \delta[\mathrm{ppm}]: 31.4,32.4,33.9,61.0,74.3(\mathrm{CH}), 81.2(\mathrm{C}), 125.0,134.3,145.6$, and 152.4.

Compound 5.

$0.15 \mathrm{~g}$ of alkyne $4(0.187 \mathrm{mmol}), 0.329 \mathrm{~g}$ of the azide $3(0.749 \mathrm{mmol}), 7 \mathrm{mg}$ of the catalyst [CuBr$\left.\left(\mathrm{PPh}_{3}\right)_{3}\right](0.0076 \mathrm{mmol})$, and $1 \mathrm{~mL}$ of dry trimethylamine were poured in $2 \mathrm{~mL}$ THF. The resulting solution was refluxed for 24 hours at $80^{\circ} \mathrm{C}$. The reaction mixture was allowed to cool and then concentrated under vacuum. After the addition of cold pentane, the mixture was filtered over Celite, and then the filtrate was concentrated to afford the title compound with $95 \%$ yield.

${ }^{1} \mathrm{H}$ NMR $(400 \mathrm{MHz}, \mathrm{CDCl} 3) \delta[\mathrm{ppm}]: 0.90(\mathrm{~m}, 24 \mathrm{H}, \mathrm{CH} 2-\mathrm{CH} 3), 1.05(\mathrm{~m}, 36 \mathrm{H}, \mathrm{C}-\mathrm{CH} 3), 1.28(\mathrm{~m}, 80 \mathrm{H},(\mathrm{CH} 2) 5), 1.53(\mathrm{~m}, 16 \mathrm{H},(\mathrm{NH}-\mathrm{CH} 2-\mathrm{CH} 2-$ hexyl)), $2.11(\mathrm{~m}, 8 \mathrm{H}, \mathrm{NH}-\mathrm{CH} 2-\mathrm{CH} 2-\mathrm{CH} 2-\mathrm{TZ}), 2.97$ (d, 4H, J = 12.5, Ar-CH2-Ar), 3.11 (t, 8H, J = 8 Hz, NH-CH2-heptyl), 3.30 (m, $16 \mathrm{H}, \mathrm{N}-\mathrm{CH} 2-$ heptyl + $\mathrm{CH} 2-\mathrm{NH}-\mathrm{CO}), 4.09(\mathrm{~s}, 8 \mathrm{H}, \mathrm{CO}-\mathrm{CH} 2-\mathrm{O}), 4.19(\mathrm{~d}, 4 \mathrm{H}, \mathrm{J}=12.5, \mathrm{Ar}-\mathrm{CH} 2-\mathrm{Ar}$ ), $4.27(\mathrm{~s}, 8 \mathrm{H}, \mathrm{O}-\mathrm{CH} 2-\mathrm{CO}), 4.44(\mathrm{t}, 8 \mathrm{H}, \mathrm{J}=6.8, \mathrm{CH} 2-\mathrm{TZ})$, 5.04 (s, 8H, O-CH2-TZ), 6.71 (s, 8H, Ar-H), 7.92 (s, 4H, TZ-H), 8.04 (bs, 4H, NH-CO).

${ }^{13} \mathrm{C}$ NMR $(100 \mathrm{MHz}, \mathrm{CDCl} 3) \delta$ [ppm]: 14.0, 14.1, 22.6, 26.9, 27.0, 27.6, 28.9, 29.1, 29.2, 29.3, 29.4, 31.4, 31.7, 31.8, 33.8, 35.9, 46.2, 46.9, $47.0,47.7,66.5,69.6,71.7,124.8,124.9,134.0,144.4,(144.9 \mathrm{C}-\mathrm{TZ}), 152.1,168.2(\mathrm{CO}-\mathrm{NH})$, and $170.0(\mathrm{CO}-\mathrm{N})$.

FT-IR (ATR crystal): $\left(\mathrm{cm}^{-1}\right) 1645$ (C=0).

MS: calcd (\%) for $\mathrm{C}_{148} \mathrm{H}_{244} \mathrm{~N}_{20} \mathrm{O}_{16}$ : 2559.7. ESI (m/z): 2560[M + H]+. Anal.: calcd (\%) for $\mathrm{C}_{148} \mathrm{H}_{244} \mathrm{~N}_{20} \mathrm{O}_{16}: \mathrm{C}, 69.45 ; \mathrm{H}, 9.61 ; \mathrm{N}, 10.94$. Found: $\mathrm{C}$, $69.21 ; \mathrm{H}, 9.52 ; \mathrm{N}, 11.12$.

\section{Solvent extraction procedure}

Lanthanide ( $\mathrm{Ln}$ ) stock solutions were prepared at the desired acidity from $10000 \mathrm{mg} \mathrm{L}^{-1} \mathrm{ICP}$ standard (in $1 \% \mathrm{HNO}_{3}$ ) of lanthanum, europium and ytterbium. A synthetic solution mimicking the leaching of the magnet was prepared from $1000 \mathrm{mg} \mathrm{L}^{-1} \mathrm{ICP}$ standard (in $1 \% \mathrm{HNO}_{3}$ ) of neodymium, dysprosium, iron and boron. The desired concentrations were prepared by dilution using ultrapure water (Milli- $\mathrm{Q}^{\circledR}$, Millipore, $18 \mathrm{M} \Omega \mathrm{cm}$ ) and the acidity was adjusted with nitric acid.

Different organic solutions were prepared from CR4-TZ-DODGA and C4-TZ-DODGA at the specific concentration in [EOPip]NTf2/octanol $(9 / 1 \mathrm{v} / \mathrm{v})$. The ionic liquid (IL) N-octyl-Nethylpiperidinium bis(trifluoromethylsulfonyl)imide ([EOPip]NTf2) was synthesized following the procedure described in the literature. ${ }^{48}$ Octanol was used to enhance the solubility of the cavitands, decrease the viscosity of the IL, and as a phase modifier in order to prevent the formation of the third phase. Organic phases were pre-equilibrated with the aqueous phase at the same acidity as the extraction step without Ln cations. The pre-equilibrated organic phases were then brought into contact with an equal volume of an aqueous acidic stock solution of $\mathrm{Ln}$ in a thermostated shaker (Infor-ht ${ }^{\circledR}$ ecotron) at $25^{\circ} \mathrm{C}$ and $400 \mathrm{rpm}$; it was ensured that equilibrium was reached within one hour. Phases were separated after centrifugation at 4000 rpm for 30 minutes (sigma 3-16 PK). After centrifugation, the separated aqueous phases were subjected to ICP-AES analysis in order to determine the distribution ratio (DM), which is the ratio of the total concentration of metal $\mathrm{M}$ in the organic phase to the total concentration of the same metal in the aqueous phase, i.e. $\mathrm{D}_{\mathrm{M}}=\left[\mathrm{M}_{\mathrm{org}}\right] /\left[\mathrm{M}_{\mathrm{aq}}\right]$. The experiments were carried out in duplicate measurements with a precision of $\pm 5 \%$.

\section{Back-extraction experiments}

The loaded organic phase was stripped with a solution of ammonium carbonate, ammonium oxalate (typically $0.5 \mathrm{M}$ ) or pure water (Milli$\left.\mathrm{Q}^{\circledast}\right)$. Back-extractions were performed at room temperature $\left(22-24{ }^{\circ} \mathrm{C}\right)$ by bringing into contact equal volumes of organic and aqueous phases over 1 hour (ratio of the aqueous over organic phase A/O = 1). After separation by centrifugation ( $4000 \mathrm{rpm}$ for $10 \mathrm{~min}$ ), the metal concentrations was measured in the aqueous phase by ICP/AES. 


\section{Conclusions}

Two ligands, CR4-TZ-DODGA and C4-TZ-DODGA, derived from the resorcin[4]arene cavitand and calix[4]arene functionalized with four diglycolamide (DGA) binding units containing n-octyl groups, were synthesized with satisfactory yield (>60\%).

In order to compare the selectivity of the ligands, light (La), medium (Eu) and heavy (Yb) cations are chosen as representatives of the beginning, middle and end of the $4 \mathrm{f}$-series. Both the ligands showed an efficiency toward the extraction of medium and heavy lanthanides using a diluent based on an ionic liquid (IL) N-octyl-N-ethylpiperidinium bis(trifluoromethylsulfonyl)imide ([EOPip]NTf2) with 10\% v. of octanol.

Under specific conditions, more than $98 \%$ of $\mathrm{Yb}$ and Eu can be extracted in comparison with $18 \%$ for La. We illustrated that such an ionic liquid-based extraction system using diglycolamide functionalized macrocyclic platforms provided selectivity for the heavier and middle lanthanides while for the conventional diglycolamide ligand such as TODGA in IL systems no specific selectivity has been observed. ${ }^{14}$ The various findings suggest that the lanthanides can be extracted via a combination of the ion pair complex formation and ion-exchange mechanism. Indeed, the decrease of efficiency with increasing feed acidity suggests an ion exchange mechanism and the absence of anion and cation exchange at low acidity suggests a neutral complex partitioning. No concrete evidence allows the discrimination between the mechanisms and the extraction pathway is probably driven by the acidity of feed solution.

From various experiments, we presume that the solvation is the mechanism involved in the extraction at low acidity $\left(0.01 \mathrm{M} \mathrm{HNO}_{3}\right)$ with 1 : 1 (metal/ligand) stoichiometry for the predominantly extracted species.

The conformational changes between a resorcin[4]arene and a calix[4]arene platform did not have a significant impact on the performance or the extraction mechanism. Indeed, a similar trend and efficiencies have been obtained for both ligands. The system used in this study exhibits promising results in regard to the extraction and recovery of $\mathrm{Nd}$ and Dy from a simulated leaching solution of a $\mathrm{Nd} / \mathrm{Fe} / \mathrm{B} / \mathrm{Dy}$ magnet. In comparison with the previous result obtained in a classical organic diluent, it appears that the replacement of toluene by the IL leads to an increase in the individual extraction capabilities. Even a lower ligand concentration leads to a distribution ratio improvement in IL compared to toluene.

\section{Conflicts of interest}

There are no conflicts to declare.

\section{Acknowledgements}

The authors acknowledge B. Baus-Lagarde for technical support. We gratefully acknowledge the financial support for this project by the Lebanese University, CEDRE program, CNRSL (the National Council for Scientific Research, Lebanon), French CNRS, Montpellier University and the Labex Project CheMISyst (ANR-10-LABX-05-01).

\section{Notes and references}

1 Rare Earths: Global Industry, Markets \& Outlook, Roskill Information Services, 2015.

2 Report on critical raw materials for the EU, Critical raw materials profiles, European Commission, 2010.

3 K. Binnemans, P. T. Jones, B. Blanpain, T. Van Gerven, Y. Yang, A. Walton and M. Buchert, J. Cleaner Prod., 2013, 51, 1-22.

4 A. E. Visser, W. M. Reichert, R. P. Swatloski, H. D. Willauer, J. G. Huddleston and R. D. Rogers, in lonic Liquids: Industrial Applications for Green Chemistry, ed. R. D. Rogers and K. R. Seddon, 2002, vol. 818, pp. 289-308.

5 J. G. Huddleston, H. D. Willauer, R. P. Swatloski, A. E. Visser and R. D. Rogers, Chem. Commun., 1998, 11, 1765-1766.

6 J. F. Brennecke and E. J. Maginn, AIChE J., 2001, 47, 2384- 2389.

7 M. L. Dietz, Sep. Sci. Technol., 2006, 41, 2047-2063.

8 S. Panja, P. K. Mohapatra, S. C. Tripathi, P. M. Gandhi and P. Janardan, Sep. Purif. Technol., 2012, 96, 289-295.

9 I. Billard, A. Ouadi and C. Gaillard, Dalton Trans., 2013, 42, 6203-6212.

10 C. H. C. Janssen, N. A. Macias-Ruvalcaba, M. Aguilar-Martinez and M. N. Kobrak, Int. Rev. Phys. Chem., 2015, 34, 591-622.

11 S. Dai, Y. H. Ju and C. E. Barnes, J. Chem. Soc., Dalton Trans., 1999, 1201-1202.

12 A. E. Visser, M. P. Jensen, I. Laszak, K. L. Nash, G. R. Choppin and R. D. Rogers, Inorg. Chem., 2003, 42, 2197-2199.

13 V. A. Cocalia, K. E. Gutowski and R. D. Rogers, Coord. Chem. Rev., 2006, 250, 755-764.

14 K. Shimojo, K. Kurahashi and H. Naganawa, Dalton Trans., 2008, 37, 5083-5088.

15 M. Bonnaffe-Moity, A. Ouadi, V. Mazan, S. Miroshnichenko, D. Ternova, S. Georg, M. Sypula, C. Gaillard and I. Billard, Dalton Trans., 2012, 41, 7526-7536.

16 A. B. Patil, P. Pathak, V. S. Shinde, S. V. Godbole and P. K. Mohapatra, Dalton Trans., 2013, 42, 1519-1529.

17 X. Sun, D. Wu, J. Chen and D. Li, J. Chem. Technol. Biotechnol., 2007, 82, 267-272.

18 R. Turgis, G. Arrachart, V. Dubois, S. Dourdain, D. Virieux, S. Michel, S. Legeai, M. Lejeune, M. Draye and S. Pellet- Rostaing, Dalton Trans., 2016, 45, 1259-1268.

19 S. A. Ansari, P. K. Mohapatra, V. Mazan and I. Billard, RSC Adv., 2015, 5, 35821-35829. 
20 T. Sukhbaatar, S. Dourdain, R. Turgis, J. Rey, G. Arrachart and S. Pellet-Rostaing, Chem. Commun., 2015, 51, $15960-15963$.

21 H. Stephan, K. Gloe, J. Beger and P. Mühl, Solvent Extr. Ion Exch., 1991, 9, 435-458.

22 H. Stephan, K. Gloe, J. Beger and P. Mühl, Solvent Extr. Ion Exch., 1991, 9, 459-469.

23 H. H. Dam, D. N. Reinhoudt and W. Verboom, Chem. Soc. Rev., 2007, 36, 367-377.

24 S. A. Ansari, P. Pathak, P. K. Mohapatra and V. K. Manchanda, Sep. Purif. Rev., 2011, 40, 43-76.

25 Z. Kolarik, Chem. Rev., 2008, 108, 4208-4252.

26 A. Sengupta, P. K. Mohapatra, M. Iqbal, J. Huskens and W. Verboom, Dalton Trans., 2012, 41, 6970-6979.

27 H. H. Dam, D. N. Reinhoudt and W. Verboom, New J. Chem., 2007, 31, 1620-1632.

28 M. Iqbal, P. K. Mohapatra, S. A. Ansari, J. Huskens and W. Verboom, Tetrahedron, 2012, 68, 7840-7847.

29 P. K. Mohapatra, A. Sengupta, M. Iqbal, J. Huskens and W. Verboom, Inorg. Chem., 2013, 52, 2533-2541.

30 M. Wehbie, G. Arrachart, I. Karamé, L. Ghannam and S. Pellet-Rostaing, Sep. Purif. Technol., 2016, 169, 17-24.

31 M. Wehbie, G. Arrachart, I. Karame, L. Ghannam and S. Pellet-Rostaing, New J. Chem., 2016, 40, 9344-9351.

32 M. J. Chetcuti, A. M. J. Devoille, A. B. Othman, R. Souane, P. Thuery and J. Vicens, Dalton Trans., 2009, 2999-3008.

33 T. Zhou, L. Chen, Y. Ye, L. Chen, Z. Qi, H. Freund and K. Sundmacher, Ind. Eng. Chem. Res., 2012, 51, 6256-6264.

34 J. Ranke, A. Othman, P. Fan and A. Müller, Int. J. Mol. Sci., 2009, 10, 1271-1289.

35 M. Wehbie, G. Arrachart, I. Karamé, L. Ghannam and S. Pellet-Rostaing, Sep. Purif. Technol., 2017, 187, 311-318.

36 R. G. Pearson, J. Chem. Educ., 1968, 45, 581-587.

37 K. L. Nash, Solvent Extr. Ion Exch., 1993, 11, 729-768.

38 H. Narita, T. Yaita and S. Tachimori, Solvent Extr. Ion Exch., 2004, 22, 135-145.

39 V. A. Cocalia, M. P. Jensen, J. D. Holbrey, S. K. Spear, D. C. Stepinski and R. D. Rogers, Dalton Trans., 2005, 11, $1966-1971$.

40 S. A. Ansari, P. K. Mohapatra, A. Sengupta, N. I. Nikishkin, J. Huskens and W. Verboom, Eur. J. Inorg. Chem., 2014, 33, 5689-5697.

41 M. L. Dietz, J. A. Dzielawa, I. Laszak, B. A. Young and M. P. Jensen, Green Chem., 2003, 5, 682-685.

42 Y. Sasaki, Y. Sugo, S. Suzuki and S. Tachimori, Solvent Extr. Ion Exch., 2001, 19, 91-103.

43 A. Sengupta, P. K. Mohapatra, M. Iqbal, J. Huskens and W. Verboom, Supramol. Chem., 2013, 25, 688-695.

44 S. A. Ansari, P. K. Mohapatra, S. M. Ali, A. Sengupta, A. Bhattacharyya and W. Verboom, Dalton Trans., 2016, 45, 5425-5429.

45 D. R. Raut, P. K. Mohapatra, S. A. Ansari, S. V. Godbole, M. Iqbal, D. Manna, T. K. Ghanty, J. Huskens and W. Verboom, RSC Adv., 2013, 3, 9296-9303.

46 R. Srinivasan, L. P. Tan, H. Wu, P.-Y. Yang, K. A. Kalesh and S. Q. Yao, Org. Biomol. Chem., 2009, 7, 1821-1828.

47 S. Taktak, R. Weissleder and L. Josephson, Langmuir, 2008, 24, 7596-7598.

48 G. Chatel, C. Goux-Henry, A. Mirabaud, T. Rossi, N. Kardos, B. Andrioletti and M. Draye, J. Catal., 2012, 291, 127-132. 